\title{
Treatment of chylothorax by producing pleurodesis using iodized talc
}

\author{
J . C. G IN GE L L ${ }^{1}$ \\ From the Thoracic Centre, Sully Hospital, Penarth, Glamorgan
}

Although a comparatively rare condition, the incidence of chylothorax is increasing. Reviewing the world literature from 1695 to 1936 , Shackelford and Fisher (1938) found 41 cases of chylothorax; Lampson (1948) reported 18 recorded cases from 1936 to 1948 and Goorwitch (1955) described a further 31 cases from 1948 to 1954 . In 1959 Schmidt published details of 92 cases found in the literature between 1953 and 1957 ; this is the most recent series and is the largest number recorded. Schmidt attributed this increase in incidence mainly to surgical trauma to the thoracic duct sustained during intrathoracic operations, in which there has been a sharp increase in recent years. Maloney and Spencer (1956), in a review of 2,660 cardiovascular operations performed in the Johns Hopkins Hospital, collected 13 cases of chylothorax after surgery. Steiger, Weinberg, and Fell (1960) reported a comparable incidence and concluded that operations requiring dissection in the vicinity of the left subclavian artery were most likely to be followed by this complication.

Despite the increasing incidence of chylothorax, opinions are divided as to the best management of this condition. Lampson (1948) performed the first successful ligation of the thoracic duct for chylothorax, and this method has since proved to be safe and effective. In the series of 92 cases reviewed by Schmidt (1959), 42 were treated by ligation of the thoracic duct, producing a cure in 39 ; there were three recurrences and no deaths. The remaining 50 cases were treated conservatively, either by repeated pleural aspirations or catheter drainage, resulting in 36 cures; there were three recurrences and 11 deaths, but only four deaths could be attributed to the chylothorax. The better results obtained by conservative treatment in recent years, as compared with a previous mortality rate approaching $50 \%$ in Shackelford and Fisher's series (1938), indicates that a trial of conservative treatment should be undertaken

1 Now at Llandough Hospital, Llandough, nr. Cardiff before ligation of the thoracic duct is performed. At the present time this is the most widely accepted view regarding the management of this condition; most authorities regard a trial of conservative measures for two weeks as indicated before ligation is considered. Maloney and Spencer (1956), however, effected cures in 11 of 13 cases of chylothorax by conservative measures and pointed out that if two weeks was the criterion to be observed then eight of the 13 cases would have required operation. They advised that a trial of conservative measures for at least three to four weeks should precede any decision in favour of surgical intervention. Schmidt (1959) found that the average interval between diagnosis and recovery after conservative treatment was 53 days.

An inability to maintain hydration and nutrition due to excessive loss of fluid, protein, and fat in the extravasated chyle, despite supportive dietary and/or intravenous therapy, is an important factor in influencing the decision to abandon conservative therapy for ligation of the thoracic duct. This situation may develop insidiously or rapidly, depending on the frequency with which pleural aspiration of chyle becomes necessary to maintain adequate pulmonary function.

It is better to prevent the development of inanition by adopting a definitive method of treatment immediately after the diagnosis of chylothorax ; this would obviate a protracted course of repeated aspirations or thoractomy for ligation of the thoracic duct. Three cases of chylothorax successfully treated by pleurodesis utilizing iodized talc are presented.

\section{CASE REPORTS}

CASE 1 A woman of 68 years was referred on 17 December 1956 with a diagnosis of right-sided chylothorax, which was confirmed by pleural aspiration. She gave a history of progressive breathlessness on exertion for eight months, until just before admission she was breathless at rest. She also complained of weakness, anorexia, and a considerable loss of weight. 
She noticed that she had developed some ankle swelling and in addition complained of palpitations and occasional episodes of giddiness. On examination she was observed to be pale with evidence of a recent loss of weight. There was pitting oedema of her legs up to mid-thigh level and there was slight sacral oedema. Her pulse rate was $112 /$ minute and regular, and the blood pressure was $140 / 90 \mathrm{~mm}$. Hg. Clinical and radiological examination of the chest confirmed the presence of an extensive right pleural effusion (Fig. 1). The abdomen was obese with no detectable

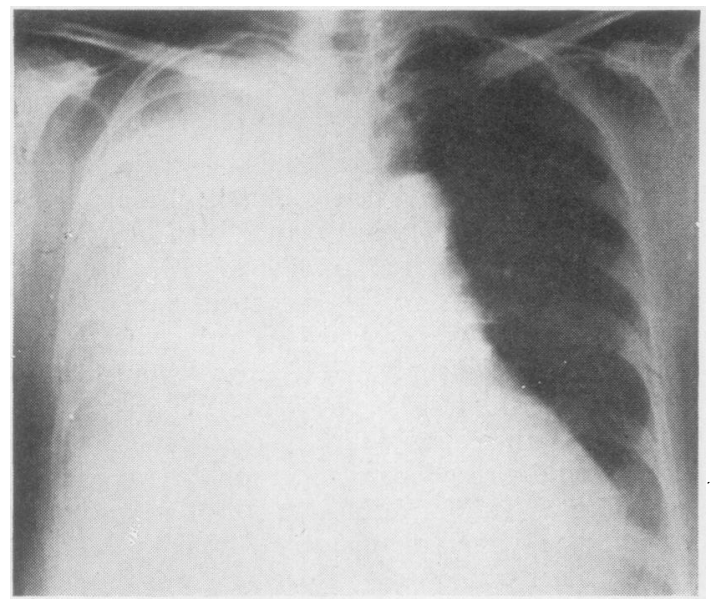

FIG. 1. Case 1. Chest radiograph showing right-sided chylothorax.

abnormalities on examination. The haemoglobin was $77 \%$ and the white cell count was 5,900/c.mm., of which $77 \%$ were neutrophils, $12 \%$ lymphocytes, $10 \%$ monocytes, and $1 \%$ basophils. The serum albumin was 1.9 g. $/ 100 \mathrm{ml}$., and globulin $1.0 \mathrm{~g} . / 100 \mathrm{ml}$.

On 19 December 1956 an intercostal tube was inserted into the right pleural cavity ander local anaesthesia using a trocar and cannula, and a large quantity of milky chyle was obtained. The tube was connected to an underwater seal and allowed to drain for several days before it was removed; however, reaccumulation of chyle occurred and a further 31 . of slightly blood-stained chyle was aspirated from the right pleural cavity. The patient was discharged home the next day with an unsubstantiated diagnosis of mediastinal malignancy; in view of her age and poor general condition, further investigation was not undertaken. As her subsequent clinical course was better than anticipated had this diagnosis been correct, she was readmitted on 20 July 1957 for further investigation.

Since her previous admission she had been forced to limit her activities considerably due to breathlessness and was barely ambulant. On examination her general condition had shown no further deterioration and the clinical features were as found on the pre- vious admission. The haemoglobin was $88 \%$ and the leucocyte count was $8,000 /$ c.mm., of which $69 \%$ were neutrophils, $24 \%$ lymphocytes, and $7 \%$ monocytes. The liver function tests and urine examination were normal. Chest radiography confirmed the persistence of the large right chylothorax. A barium swallow examination showed no evidence of any intrinsic oesophageal lesion or compression by extrinsic glandular enlargement, and no abnormality was shown in the stomach or duodenum. Post-aspiration chest radiographs failed to show any evidence of a primary condition in the right lung. Re-accumulation of chyle rapidly occurred after pleural aspirations; further measures were not undertaken and the patient was discharged home on 10 August 1957.

No further significant deterioration in her condition was noted over the ensuing months; she remained dyspnoeic and weak with dependent oedema, and it was decided to readmit her and on this occasion to perform poudrage with iodized talc. Clinical and radiological examination on readmission on 4 December 1957 revealed no new features; the persistence of chyle in the right pleural cavity was confirmed by the aspiration of 21 . of typical milky fluid which was followed by rapid re-accumulation over the next few days.

On 11 December 1957, under general anaesthesia, a trocar and cannula were inserted into the right pleural cavity via a stab incision, and 41 . of chyle was aspirated through the cannula. Iodized talc, $5 \mathrm{~g}$., was insufflated into the pleural cavity and an intercostal tube was inserted (Fig. 2). This was connected to an underwater seal and suction drainage was instituted and maintained until 16 December 1957, when drainage of chyle had ceased and the tube was removed. Subsequent radiographs of the chest showed the lung to be fully expanded (Fig. 3), and no further

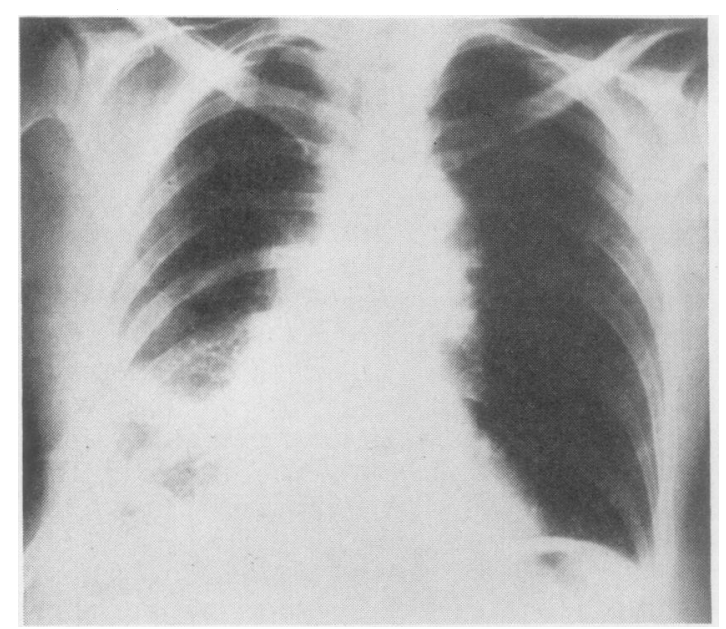

FIG. 2. Case 1. Radiograph of chest after the insertion of an intercostal tube. 


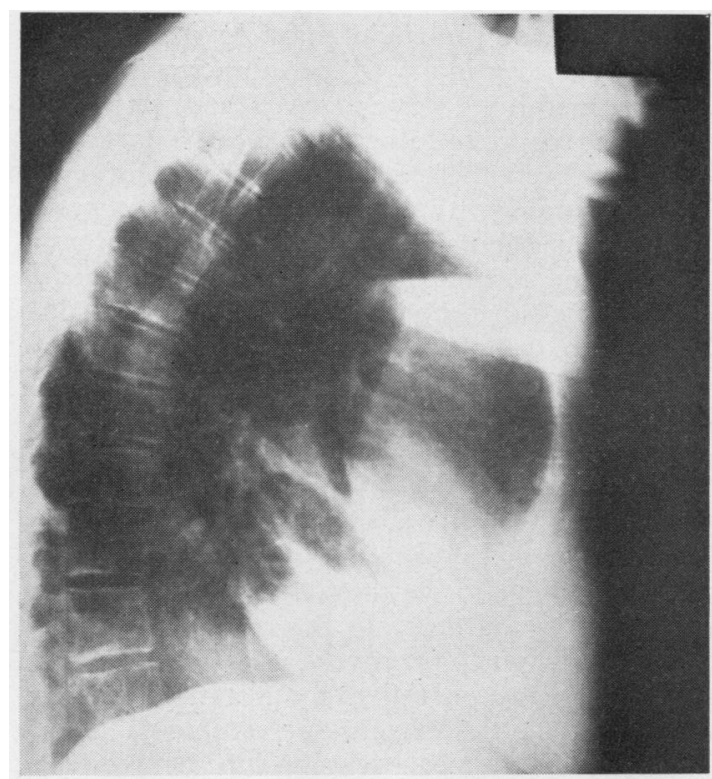

FIG. 3. Case 1. Right lateral chest radiograph after removal of the intercostal tube, showing full expansion of the lung with a small anterior loculated collection of chyle.

accumulation of chyle occurred; she was discharged home on 2 January 1958 and has had no recurrence of the condition to the present time.

The aetiology of the chylothorax in this case was undetermined and is probably in the large group labelled spontaneous or idiopathic.

CASE 2 This patient, aged 76 years, was admitted on 17 July 1963 with a six-week history of dysphagia, anorexia, and one stone loss in weight. Clinical examination revealed a healthy looking man for his age; there was no anaemia or lymphadenopathy. The pulse rate was $80 /$ minute with occasional extrasystoles and some arterial wall thickening. The blood pressure was $170 / 95 \mathrm{~mm}$. $\mathrm{Hg}$; there were no abnormal physical signs on examination of the respiratory system and abdomen. The clinical diagnosis of carcinoma of the oesophagus was confirmed on barium swallow examination which revealed an irregular filling defect of the lower third of the oesophagus. At operation on 26 July 1963 the carcinoma was found to be invading the left mediastinal pleura and the lung; the remainder of the tumour was mobilized and resection was possible. Oesophago-gastrostomy was performed, the anastomosis being made lateral to the aortic arch ; pylorotomy was also performed and the chest was closed in layers with two intercostal tubes draining the pleural cavity.
Initially, the post-operative course was uneventful ; the intercostal tubes were shortened and removed. Intravenous therapy was discontinued and a light semi-solid diet was commenced. On 4 August 1963, nine days post-operatively, examination of the chest revealed a left-sided pleural effusion which increased in size during the next few days and was associated with increasing breathlessness (Fig. 4). Pleural aspiration was performed on 7 August 1963, when a quantity of milky chyle was removed; this was confirmed on laboratory examination. Under local anaesthesia an intercostal tube was inserted and connected to an underwater seal ; $600 \mathrm{ml}$. of chyle drained in the ensuing 24 hours before the tube

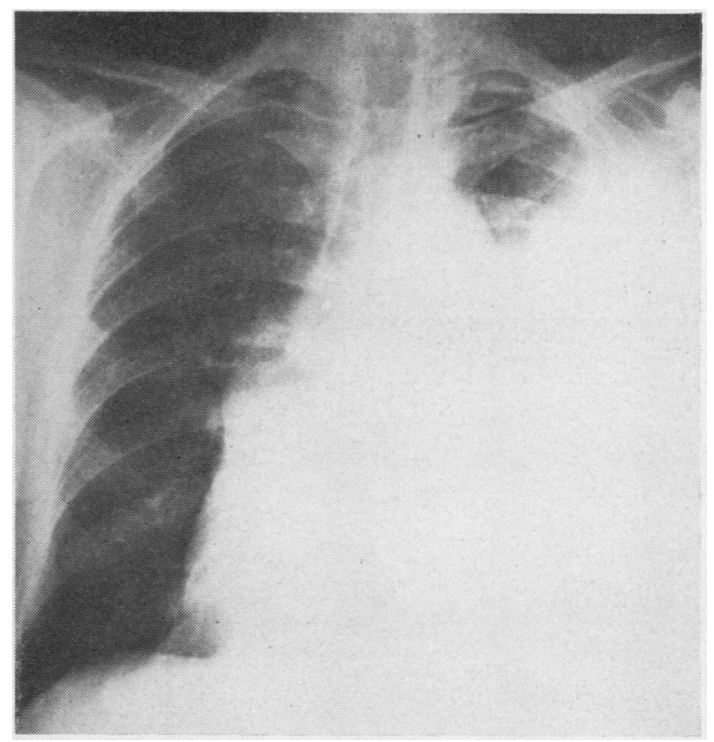

FIG. 4. Case 2. Chest radiograph showing left-sided chylothorax after gastro-oesophagectomy.

inadvertently slipped out of the chest. Pleural aspiration was again necessary on 10 August when a further $1,200 \mathrm{ml}$. of chylous fluid was obtained. Re-accumulation occurred, however, and on 13 August, under general anaesthesia, a trocar and cannula were inserted into the left pleural cavity and 21 . of chyle was aspirated; $5 \mathrm{~g}$. of iodized talc was insufflated into the pleural cavity and a single intercostal tube was inserted and connected to an underwater seal. Continuous gentle suction was applied to the tube until 21 August, when it was removed. Chest radiographs after removal showed a small residual effusion (Fig. 5), but no re-accumulation occurred and further clearing was observed radiologically before his discharge home on 1 September. When he was seen on 29 October there was no evidence of recurrence of chylothorax. 

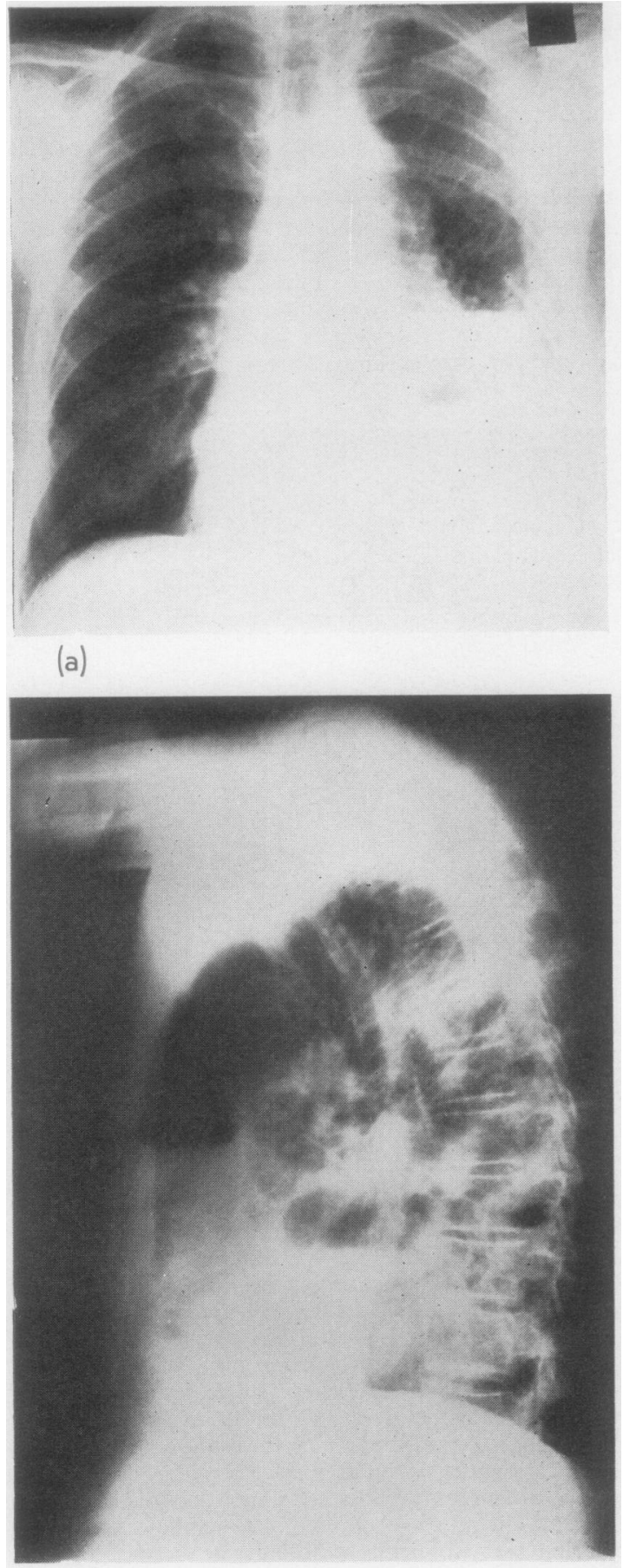

(b)

FIG. 5. Case 2. (a) Postero-anterior and (b) left lateral chest radiographs showing small residual anterior effusion.
The cause of the chylothorax in this case was thought to be an injury to the thoracic duct at the time of operation. Steiger et al. (1960) stated that it is usual for there to be a three to 10 days delay post-operatively before the appearance of chyle in the pleural cavity after trauma to the thoracic duct and its tributaries. The delay has been attributed to the accumulation of chyle in the mediastinum which then breaks through the mediastinal pleura into the pleural cavity when the pressure attained is sufficient. In the case reported by Brown (1937), chest radiographs were submitted illustrating this course of events. It is known that the flow of chyle is substantially increased by oral feeding (Crandall, Barker, and Graham, 1943), and the delay in the appearance of chylothorax after surgical damage to the thoracic duct may, in part, be related to the delay in the commencement of oral feeding post-operatively. Chylothorax is an uncommon post-operative complication after resections of the oesophagus for carcinoma despite the close anatomical relationship between the oesophagus and the thoracic duct and the extensive dissection often necessary to mobilize the tumour. Wu, Howe, Hwang, and Liu (1955) report two cases of post-operative chylothorax in a series of 79 oesophageal resections, and in both patients the operation was for carcinoma of the middle third.

CASE 3 This patient was a married woman of 18 years who had had a full-term normal delivery of a 7 lb. baby on 24 June 1963 after a normal pregnancy during which she felt well. She remained well during the first month post-natally, but then noticed that she lacked energy and was unable to manage her housework. This feeling of lethargy persisted and she found that she was becoming increasingly breathless on exertion. At this time she also experienced a stabbing pain in the epigastrium; this was not pleuritic and was unrelated to meals, posture or exercise. The dyspnoea and tiredness became more marked during the next few months and she developed a cough productive of mucoid sputum; she lost 1 stone (6.35 kg.) in weight. An out-patient chest radiograph arranged by her general practitioner revealed large bilateral pleural effusions; she was admitted to her local hospital on 18 September 1963, approximately two and a half months after the onset of symptoms.

Several chest aspirations were performed and on each occasion several litres of what was described as 'thin pus' was obtained; this proved to be sterile on culture. Although she was Mantoux negative and tubercle bacilli were not found in the sputum or the pleural fluid, antituberculous therapy in addition to penicillin was begun. She failed to improve, the effusions persisted, and she was transferred to sully Hospital on 30 September 1963. 
On admission examination revealed a weak, illlooking woman with a cyanotic tinge to her lips and nail beds. There was a noticeable malar flush and she was very dyspnoeic at rest. The jugular venous pressure was not raised and there was no sacral or ankle oedema. Several small, discrete, soft, mobile lymph nodes were palpable in both supraclavicular fossae. She had a regular tachycardia of $112 / \mathrm{min}$. and the blood pressure was $100 / 40 \mathrm{~mm}$. $\mathrm{Hg}$. Clinical examination of the chest revealed the physical signs of large, bilateral pleural effusions confirmed on radiography (Fig. 6). Examination of the abdomen was normal.

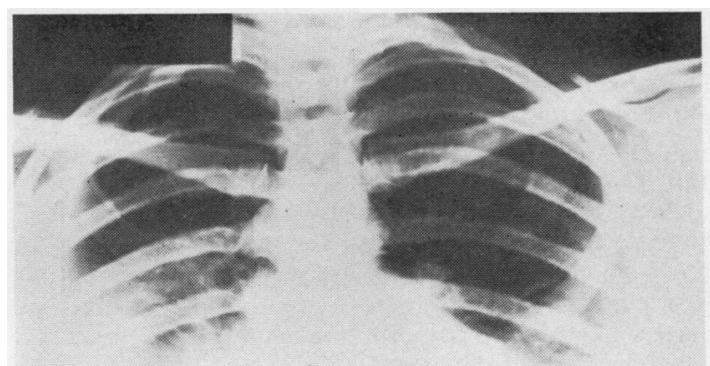

FIG. 6. Case 3. Chest radiograph showing bilateral chylothorax.

The haemoglobin was $18 \cdot 1 \mathrm{~g} . / 100 \mathrm{ml}$. (124\%) and the packed cell volume $55 \%$; the absolute values were: M.C.V. 83 c. $\mu$, M.C.H. $29 \mu \mu$ g., M.C.H.C. $34 \%$ and the colour index normal. W.B.C. $6,700 /$ c.mm. with a normal differential count; no abnormal leucocytes were seen. The serum electrolytes were: sodium $136 \mathrm{mEq} /$ litre, potassium $3.9 \mathrm{mEq} /$ litre, and chloride $92 \mathrm{mEq} /$ litre; the blood urea was $27 \mathrm{mg} . / 100 \mathrm{ml}$. The total plasma protein was $6.3 \mathrm{~g} . / 100 \mathrm{ml}$. and the electrophoretic pattern was normal. The liver function tests were normal, and urine examination was negative. The sputum cultured no pathogens and acid-fast bacilli were not found on microscopy. Pleural aspiration revealed typical chylous fluid, confirmed on laboratory examination, and during the ensuing nine days six pleural aspirations were performed and a total of 8.7 litres of chyle was obtained (Table I).

Re-accumulation was rapid, her condition remained poor, and it became obvious that something other than repeated aspirations would have to be employed. The policy planned was supraclavicular node biopsy under general anaesthesia combined with frozen section histological examination. If the node showed
T A B L E I

SUMMARY OF THE VOLUMES OF ASPIRATE

\begin{tabular}{|c|c|c|}
\hline Date & Side & Amount Aspirated \\
\hline 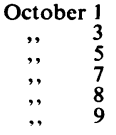 & $\begin{array}{l}\text { Right } \\
\text { Left } \\
\text { Right } \\
\text { Right } \\
\text { Left } \\
\text { Right }\end{array}$ & $\begin{array}{l}1,500 \mathrm{ml} . \\
550 \mathrm{ml} . \\
1,550 \mathrm{ml} . \\
1,900 \mathrm{ml} . \\
1,600 \mathrm{ml} . \\
1,600 \mathrm{ml} .\end{array}$ \\
\hline & $\begin{array}{l}\text { Total } \\
\text { Average }\end{array}$ & $\begin{array}{c}8,700 \mathrm{ml} \\
1.5 \text { litres a spiration }\end{array}$ \\
\hline
\end{tabular}

no evidence of a malignant lesion it was intended to use catheter drainage of the pleural cavities after poudrage with iodized talc. If tumour was found it the supraclavicular lymph node, then thoracotomy was to be carried out to determine the precise nature and extent of the causative lesion.

On 10 October operation was carried out; the histological section was reported as showing a small collection of hyperchromatic cells suggestive of malignancy (this was not confirmed on examination of paraffin sections later). On receipt of this report a right posterolateral thoracotomy was performed through the fifth intercostal space; $1,600 \mathrm{ml}$. of chyle was aspirated from the pleural cavity, but the origin of the chyle could not be ascertained. The pleura was incised overlying the posterior mediastinum and an attempt was made to identify the thoracic duct; this was not possible owing to oedema and thickening of the mediastinal connective tissue. No pathological mediastinal lymph nodes were found and no causative lesion was detected to account for the chylothorax. The left mediastinal pleura was incised and $1,500 \mathrm{ml}$. of chyle was aspirated from the left pleural cavity. The right pleural cavity was then sprinkled with $5 \mathrm{~g}$. of iodized talc, two intercostal tubes were inserted and connected to underwater seals, and the thoracotomy wound was closed in layers. The patient was then turned on to her right side and a trocar and cannula were inserted into the left pleural cavity via a stab incision. Poudrage was again performed using $5 \mathrm{~g}$. of iodized talc and an intercostal tube was inserted; this was connected to an underwater seal and the three intercostal tubes were placed on gentle suction $(5 \mathrm{~cm}$. $\mathrm{Hg})$.

Her immediate post-operative condition gave rise to considerable anxiety; the extremities were cyanosed and she was cold and clinically pulseless. A portable chest radiograph showed the lungs to be fully expanded (Fig. 7). It was concluded that the cause of her collapse was the sudden loss of a large quantity of fluid, protein, and electrolytes in the aspirated chyle at operation on top of a more gradual but considerable depletion over the previous nine days; this had resulted in peripheral circulatory failure due to dehydration and depletion of the circulating blood volume to a dangerously low level. The haemoglobin proved to be $155 \%$ and the P.C.V. was $68 \%$; the serum electrolytes and blood urea were normal and the plasma proteins $6 \mathrm{~g} . / 100 \mathrm{ml}$. Resus- 


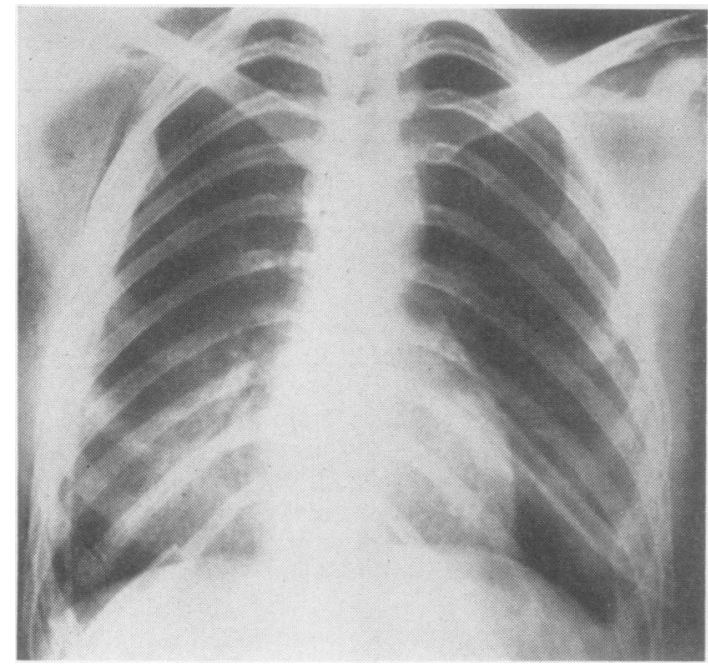

FIG. 7. Case 3. Chest radiograph after insertion of intercostal tubes.

citative measures were undertaken including the rapid intravenous administration of $5 \%$ dextrose, normal saline, and plasma ; gradual improvement in her condition occurred during the next 48 hours, after which the haemoglobin was $100 \%$ and the P.C.V. $45 \%$; the plasma proteins, which had previously appeared to be normal, were shown to be $4 \cdot 3 \mathrm{~g} . / 100 \mathrm{ml}$. with the restoration of normovolaemia. The hypoproteinaemia now apparent resulted in the development of gross sacral oedema, but this diminished after the administration of $400 \mathrm{ml}$. of double strength plasma and $22 \mathrm{~g}$. of human albumin in $400 \mathrm{ml}$. of water; an excellent diuresis was obtained, and the plasma protein level was restored to $5.8 \mathrm{~g} . / 100 \mathrm{ml}$. within the next three days.

Nothing was given orally until two days after operation, when sips of water only were allowed; up to this time very little serous drainage had occurred from the chest. With the beginning of oral milk and complan four days post-operatively there was a slight increase in drainage from the right pleural cavity and this was milky in appearance. This oral regime was discontinued, oral fluids were restricted to $1,000 \mathrm{ml}$./ 24 hours, and intravenous therapy was maintained. The left intercostal tube and the right basal tube were removed on the fifth post-operative day and the remaining tube on the next day. Chest radiography showed the lungs to be fully expanded with little pleural collection of chyle (Fig. 8). A summary of the post-operative pleural drainage is shown in Table II.

An interesting observation post-operatively was the presence of considerable oedema of the left arm associated with a distended left external jugular vein. The left external jugular vein filling was not commented upon pre-operatively although several people examined her neck in the palpation of the supraclavicular glands. It was presumed, therefore, that she
T A B L E I I

DETAILS OF POST-OPERATIVE PLEURAL DRAINAGE

\begin{tabular}{|c|c|c|c|c|}
\hline \multirow{2}{*}{ Post-operative Day } & \multicolumn{2}{|c|}{ Pleural Drainage } & \multirow{2}{*}{$\begin{array}{l}\text { Type } \\
\text { of } \\
\text { Fluid }\end{array}$} & \multirow{2}{*}{$\begin{array}{l}\text { Supportive } \\
\text { Therapy }\end{array}$} \\
\hline & Left & Right & & \\
\hline $\begin{array}{l}1 \\
2 \\
3 \\
4\end{array}$ & $\begin{array}{c}750 \mathrm{ml} . \\
150 \mathrm{ml} \\
50 \mathrm{ml} \\
0\end{array}$ & $\begin{array}{r}650 \mathrm{ml} . \\
50 \mathrm{ml} . \\
50 \mathrm{ml} . \\
300 \mathrm{ml} .\end{array}$ & $\begin{array}{l}\text { Cloudy } \\
\text { Serous } \\
\text { Serous } \\
\text { Milky }\end{array}$ & $\begin{array}{l}\text { I.V. } \\
\text { I.V. } \\
\text { I.V. } \\
\text { Oral complan } \\
\text { and milk }\end{array}$ \\
\hline $\begin{array}{l}5 \text { Left tube removed; } \\
\text { right basal tube re- } \\
\text { moved }\end{array}$ & 0 & $180 \mathrm{ml}$. & Serous & $\begin{array}{l}\text { I. }{ }_{\text {fluid orally }} 1 . \\
\text { f }\end{array}$ \\
\hline $6 \begin{array}{l}\text { Right apical tube } \\
\text { removed }\end{array}$ & 0 & 0 & - & I.V. +11 . 1 . \\
\hline
\end{tabular}

had a left subclavian vein thrombosis which may have been precipitated by the post-operative haemoconcentration. The oedema subsided over several days after elevation of the arm, but the external jugular vein remained filled.

After the initial post-operative anxiety she made an uneventful recovery and was discharged home on 15 November 1963. When last seen she was symptomless, clinical and radiological examination of the chest revealing no recurrence of the chylothorax (Fig. 9).

The aetiology in this case is again obscure as in case 1. Damage to the thoracic duct by the sharp tendinous edge of the right crus of the diaphragm with hyperextension of the dorsal spine has been postulated in a case reported by Brown (1937). Violent coughing, heavy lifting, and sudden twisting movements have all been forwarded as aetiological factors in producing damage to the

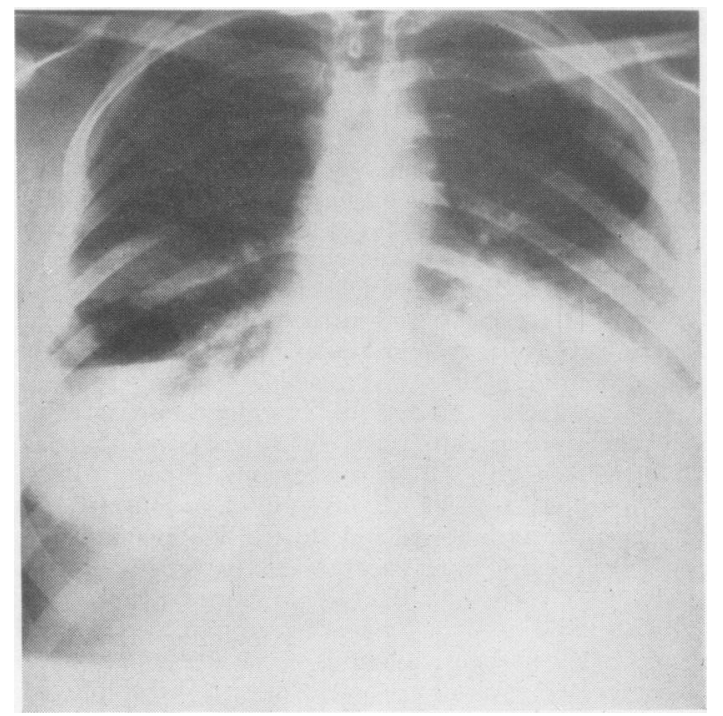

FIG. 8. Case 3. Chest radiograph on sixth post-operative day after removal of the intercostal tubes. 


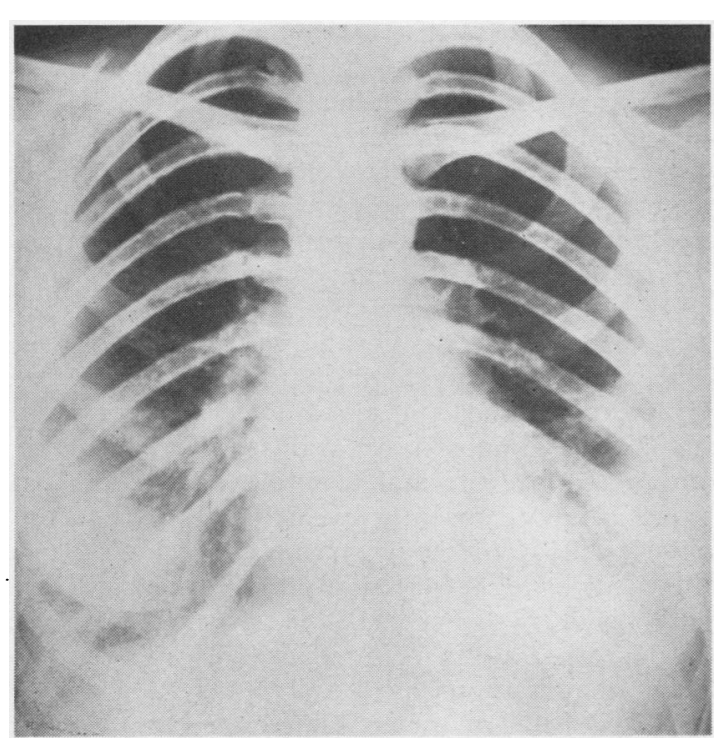

FIG. 9. Case 3. Chest radiograph seven weeks after treatment, showing some residual pleural thickening and an absence of chylothorax.

thoracic duct and chylothorax. In case 3 the chylothorax may have been due to rupture of the thoracic duct produced by raised intraductal pressure caused by muscular contractions during parturition; her symptoms appeared within one month of childbirth. Meade, Head, and Moen (1950) further postulate the prerequisite of unusual fixation of the thoracic duct by fibrosis or congenital bands for rupture of the duct to occur in these circumstances.

\section{DISCUSSION}

The principle underlying the treatment employed in these three cases was that of promoting a sterile inflammation of the pleura and at the same time maintaining full expansion of the lung; in this way the pleural space is obliterated, allowing pleural symphysis to occur. This was achieved by insufflation of iodized talc and continuous suction drainage of the pleural cavity as described.

The idea of promoting pleurodesis in the treatment of chylothorax is not new, but its potential value seems to have been overlooked. Gordon (1940) reported a case of chylothorax treated by bi-weekly chest aspirations for three months after which time the pleural cavity was irrigated with a 1 in 3,000 saline solution of azochloramide. Subsequently the patient needed only a monthly aspiration. Matson and Stacy (1940) reported a patient with chylothorax who was cured by repeated intrapleural injections of $1 \%$ gomenol in oil in association with chest aspiration. The patient had previously had 13 pleural aspirations during the month after the onset of chylothorax. Schnug and Ransohoff (1943) successfully treated a case of chylothorax with an intrapleural injection of $50 \mathrm{ml}$. of sterile broth on the thirty-second day after the onset; before this a total of 561 . of chyle had been aspirated from the chest. A right phrenicotomy had been performed on the fifteenth day but no decrease in the rate of accumulation was obtained by this procedure. The authors regarded the injection of broth and the cessation of effusion as coincidental. These cases were successful during the period when the mortality rate from chylothorax approached $50 \%$.

More recently, Randolph and Gross (1957) have drawn attention to the possible value of adhesion formation in the pleural cavity in effecting a cure of chylothorax after thoracotomy undertaken for ligation of the thoracic duct. They advocated the use of tincture of iodine to swab the mediastinal pleura in those cases of chylothorax in which multiple pleural leaks were present. They first controlled the leaks by suture and hoped that the irritating effect of iodine would aid the sealing of small unseen leaks. One case was cured by causing trauma to the mediastinal pleura without any suturing being carried out, since no leaking points were observed at operation. Williams and Burford (1963) record the use of intrapleural nitrogen mustard in one case and Aul 98 in another case of chylothorax in an attempt to speed the formation of pleurodesis; the clinical details and results are not reported. They also recommended poudrage in those cases in which the leakage from the duct or the duct itself could not be identified at thoracotomy.

The value of maintaining full expansion of the lung in the treatment of chylothorax, and obliteration of the pleural space, was recognized by Maloney and Spencer (1956). They concluded, from 13 cases of chylothorax, that one cannot be guided by a decrease in the rate of re-accumulation of chyle, as judged by repeated aspirations, as an indication that a cure is imminent and found that a sudden recovery was more usual. They suggested that this is an indication that a cure results not from gradual healing of the injured lymph duct but from obliteration of the pleural space. Therefore they advocated that attempts should be made to achieve complete aspiration of all fluid so that the visceral and parietal pleura are in apposition; this is in agreement with the views expressed by Seaman (1954). They recognized that 
closed catheter drainage, permitting continuous removal of chyle, was theoretically superior to intermittent aspiration in achieving this, but stated that this was not used because of the favourable results of simple aspirations obtained in their series.

A small minority of cases are cured without any more active treatment than several aspirations. More often repeated aspirations, and supportive measures aimed at maintaining nutrition, have to be used for several weeks before a cure is obtained. A remaining large proportion have eventually to be referred for thoracotomy and ligation of the thoracic duct when this mode of therapy has been unsuccessful. There is no way of recognizing at the onset what the outcome of expectant treatment will be in a particular case; therefore the use of poudrage and continuous suction drainage is advocated initially in preference to repeated aspirations, by which method it is impossible to keep the lung fully expanded.

Chyle is relatively non-irritating to the pleura and does not itself evoke a significant inflammatory response. The cases reported by Meade et al. (1950) and by Lawrance (1961), which required decortication to allow the lung to re-expand, had both previously had repeated pleural aspirations, and the case described by Goorwitch (1955) had had an intercostal tube in situ for two weeks. Long-standing cases of chylothorax have been reported by Klepser and Berry (1954), Maloney and Spencer (1956), and Steiger et al. (1960) in which this complication of fibrinous membrane formation over the lung was not observed at thoracotomy. No difficulty was experienced in obtaining re-expansion of the lung in my case 1 after poudrage performed one year after the onset. Pleural thickening preventing full expansion of the lung has not been recorded in previously untreated cases of chylothorax subjected to thoracotomy, and it is an infrequent occurrence in those cases treated by repeated aspirations or catheter drainage; it is a complication to be considered when conservative measures are used for a long time.

Iodized talc produces a good pleural inflammatory reaction, and suction drainage applied to the intercostal tubes removes the resultant exudate, together with any chyle leaking into the pleural cavity ; this maintains full expansion of the lung and the promotion of adhesions between the visceral and parietal pleura ; in this way any leak of chyle is sealed off quickly and effectively. Smith and Rothwell (1962) reported from Sully the use of poudrage with iodized talc and suction drainage in the treatment of recurrent spontaneous pneumothoraces; it is a safe and effective method of producing pleural symphysis used extensively at this hospital. Randolph and Gross (1957) expressed the opinion that suction drainage was an adverse procedure in chylothorax because the increased negative intrapleural pressure might tend to keep the duct fistula open; these fears seem to be unfounded in the light of my experience.

In addition to promoting pleurodesis it is also logical to reduce the flow of chyle in the thoracic duct and hence to diminish the size of the leak. This can readily be attained by using intravenous therapy as opposed to oral feeding, a method advocated by Birt and Connolly (1952) and emphasized more recently by Williams and Burford (1963). By studying a thoracic duct fistula, Crandall et al. (1943) showed that the basal rate of flow of chyle was $0.93 \mathrm{ml} . / \mathrm{min}$., which could be increased to a maximum of $3.9 \mathrm{ml} / \mathrm{min}$. by food, that is, approximately fourfold. In case 3, reported here, it was observed that there was a small increase in pleural drainage when oral feeding was begun on the fourth post-operative day ; this was deferred and intravenous supportive therapy was continued until no further drainage was obtained.

As a method of treatment repeated pleural aspirations of re-accumulating chyle has the disadvantage of uncertainty as to the duration of treatment before a cure is produced, if in fact this is achieved at all. Ligation of the thoracic duct initially without a trial of conservative therapy is not indicated. It is a major procedure which would prove to be unnecessary in a large proportion of cases. This can be appreciated by studying the series collected by Schmidt (1959) in which 36 of the 92 cases reported were cured by conservative measures alone.

The successful results obtained using iodized talc pleurodesis in the three cases of chylothorax reported here indicate the value of this method of treatment.

\section{SUMMARY}

A more active approach than repeated thoracenteses is indicated in the treatment of chylothorax with a view to reducing the period of hospitalization, preventing the development of inanition and the complication of fibrous pleural thickening which prevents full expansion of the lung. Thoracotomy and ligation of the thoracic duct is a major and often unnecessary operation.

Three cases of chylothorax are presented; they were treated effectively by the intrapleural insufflation of iodized talc combined with suction drainage of the pleural cavity. In this way the lung 
remained fully expanded, pleurodesis was produced, and the chylothorax ceased.

I wish to express my gratitude to Mr. Dillwyn M. E. Thomas for permission to publish the details of cases 1 and 3, who were under his management, and for his helpful advice and encouragement in the preparation of this paper. My thanks are also due to $\mathrm{Mr}$. H. O. Jones for permission to publish case 2 and to Dr. H. M. Foreman, under whose care case 3 was admitted to Sully Hospital. Mr. J. L. A. Dowse kindly read the proofs, and the photographs of the chest radiographs were taken by Mr. F. Midgeley.

\section{REFERENCES}

Birt, A. B., and Connolly, N. K. (1952). Traumatic chylothorax. A report of a case and a survey of the literature. Brit. J. Surg., 39, 564.

Brown, A. L. (1937). Traumatic rupture of the thoracic duct with bilateral chylothorax and chylous ascites : new operation; report of a case. Arch. Surg., 34, 120.

Crandall, L. A., Jr., Barker, S. B., and Graham, D. G. (1943). A study of the lymph flow from a patient with thoracic duct fistula. Gastroenterclozy, 1, 1040.

Goorwitch, J. (1955). Traumatic chylothorax and thoracic duct ligation. J. thorac. Surg., 29, 467.

Gordon, J. (1940). Traumatic chylothorax; case report. Ann. intern. Med., 13, 1998.

Klepser, R. G., and Berry, J. F. (1954). The diagnosis and surgical management of chylothorax with the aid of lipophilic dyes. Dis. Chest, $25,409$.

Lampson, R. S. (1948). Traumatic chylothorax ; a review of the literature and report of a case treated by mediastinal ligation of the thoracic duct. $J$. thorac. Surg., 17, 778 .

Lawrance, K. (1961). Idiopathic chylothorax. Two case reports. Brit. J. Surg., 48, 653 .

Maloney, J. V., Jr., and Spencer, F. C. (1956). The non-operative treatment of traumatic chylothorax. Surgery, 40, 121.

Matson, R. C., and Stacy, J. W. (1940). Traumatic chylothorax : case report and a new suggestion for treatment. Dis. Chest, 6, 332 .
Meade, R. H., Jr., Head, J. R., and Moen, C. W. (1950). The management of chylothorax. J. thorac. Surg., 19, 709.

Randolph, J. G., and Gross, R. E. (1957). Congenital chylothorax Arch. Surg., 74, 405.

Schmidt, A. (1959). Chylothorax : Review of 5 years' cases in the literature and report of a case. Acta chir. scand., 118, 5 .

Schnug, E., and Ransohoff, J. (1943). Traumatic chylothorax-a case treated with intravenous chyle. Surgery, 14, 278.

Seaman, J. B. (1954). Rationale and a new surgical technique in traumatic chylothorax, with report of a case. J. thorac. Surg., 27, 529 .

Shackelford, R. T., and Fisher, A. M. (1938). Traumatic chylothorax. South. med. J.'(Bgham, Ala.), 31, 766.

Smith, W. G., and Rothwell, P. P. G. (1962). Treatment of spontaneous pneumothorax. Thorax, 17, 342 .

Steiger, Z., Weinberg, M., and Fell, E. H. (1960). Post-operative chylothorax. Amer. J.'Surg., $100,8$.

Williams, K. R., and Burford, T. H. (1963). The management of chylothorax related to trauma. $J$. Trauma, 3, 317.

Wu, Y. K., Howe, Y. L., Hwang, K. C., and Liu, K. (1955). Surgical treatment of carcinoma of the esophagus and cardia of the stomach. Chin. med. J., 73, 181 .

\section{ADDENDUM}

\section{METHOD OF PREPARATION OF IODIZED TALC}

Finely sifted light kaolin is dried in a thin layer at $160^{\circ} \mathrm{C}$. for $45 \mathrm{~min}$. This is then weighed into previously dried Universal Containers, $5 \mathrm{~g}$. in each container. These are sterilized at $160^{\circ} \mathrm{C}$. for two hours and stored until required for use.

Weigh $0.1 \mathrm{~g}$. iodine and dissolve in $4 \mathrm{ml}$. anaesthetic ether. Transfer aseptically $1 \mathrm{ml}$. of this solution (i.e., 0.025 g.) iodine, to the previously sterilized kaolin. The resultant mixture is iodine $0.5 \%$ in kaolin.

Label: Poudrage $5 \mathrm{~g}$. Not to be used after .... (this date to be 24 hours after preparation). 